\title{
A Study on the Construction of Eco-corridor Based on Nature Reserves
}

\author{
Meirong Tian ${ }^{1, a}$, Guobao Song ${ }^{2}$, Jixi Gao ${ }^{1, b}$, Jie Qiu ${ }^{1}$ \\ ${ }^{1}$ Nanjing Institute of Environmental Science, Ministry of Environmental Protection, \\ Nanjing 210042, China \\ ${ }^{2}$ Key Laboratory of Industrial Ecology and Environmental Engineering (MOE), School of \\ Environmental Science and Technology, Dalian University of Technology, Dalian 116024, China \\ aemail:tianmeirong007@163.com, bemail:gaojx168@163.com
}

\section{Keywords: Nature reserves, Bio-diversity Protection, Eco-corridor}

\begin{abstract}
The scientific and reasonable construction of eco-corridors between the nature reserves will be helpful in eliminating the habitat isolation and alleviating the negative effect of landscape fragmentation towards bio-diversity and ecological security. Focusing on the nature reserves in Northeast China, in this paper, we extracted the spatial location of the areas and then applied the minimum cost-distance model to develop a connecting resistance index system in terms of land utilization, disturbance intensity and linear surface feature's resistance; the resistance surface was also developed to reflect human's disturbance, and based on the resistance surface as well as the database of the nature reserves, the eco-corridors between adjacent conservation areas were extracted by applying the minimum cost-distance method, and then the corridor network, which was important to protect the bio-diversity in the conservation areas, was obtained by loop computing.
\end{abstract}

\section{Introduction}

With the reform and opening-up in China, over-exploitation of farmland, deforestation, land reclamation from lake, urbanization and road construction have led to extensive lose for the habitats of wild fauna and flora and added degradation and fragmentation of the habitats. The fragmentation of habitats is in extremely bad condition, which has caused severe impact for bio-diversity. According to $\mathrm{Li}, 18.37 \%$ of the national territorial area had been affected by road network in varying degrees, and the quantity of patches had increased by 119.3 times [1] because of the incision of the road network; meanwhile, the shape of the patches were becoming more and more complicated and the fractal dimensions had increased. Ye etc, analyzed the relationship between major engineering and fragmentation of water habitat in Yangtze River estuary, and the results proved that human activity intensity had positive relation with fragmentation, and the deep water channel treatment project had changed the estuarine geography, sedimentary distribution, and hydrodynamic conditions and cut the big natural landscape patches into small pieces and increased the fragmentation [2]. In terms of the conservation of rare species, wild panda, white crane and oriental white stork are facing with potential threat by the increasing fragmentation of habitats. The construction of national level eco-corridors will connect the land nature reserves and contribute to the bio-diversity protection, climate adaptation and national ecological security, so many researches had been carried out [3][4][5], and the main method for constructing eco-corridors was minimum-resistance model [6][7].

Northeast area is a priority area of bio-diversity conservation in China, which also serves as the ecological security barrier of northern China. In this paper, we mainly focused on the nature reserves in Northeast China and developed a connecting resistance index system; we also developed the resistance surface by applying arcgis calculation and on this basis, we produced the eco-corridors which were able to connect the nature reserves in Northeast China, these results would provide technical support to more effective bio-diversity and resource protection. 


\section{Study area}

The study area focuses in Liaoning, Jilin and Heilongjiang provinces in Northeast China, and includes Great Khingan, lesser Khingan Mountains, Changbai Mountains, Songnen Plain and Three River Plain. The study area lies in middle and cold temperate zones and belongs to monsoon climate of medium latitudes, which has four distinctive seasons including warm, rainy summer and cold, dry winter. The annual precipitation ranges from $1000 \mathrm{~mm}$ to $300 \mathrm{~mm}$ below in humid region, half humid region and semi-arid region respectively. The study area located from $\mathrm{N} 38^{\circ} 43^{\prime} \sim$ $47^{\circ} 40^{\prime} 53^{\circ} 34^{\prime}$ and $\mathrm{E} 38^{\circ} 43^{\prime} \sim 47^{\circ} 40^{\prime} 53^{\circ} 34^{\prime}$, which has a total area of $80.84 \times 105 \mathrm{~km} 2$; Topographic type in the area mainly includes plain, upland and low mountains. The special geographic conditions and location contribute to abundant bio-diversity in the study area, which has 52 species of rare animals, 288 species (subspecies) of birds and 19 species of reptiles [8].

\section{Methods and data}

\section{Technical method and process of the least-resistance model.}

(1) Identification of ecological barriers

The characteristics of ecological barrier in the landscape are the basis for constructing least-cost model, because the resistance factors in the barrier interrupt the connectivity, so if we can identify the spatial locations which interrupt the connectivity, we will be able to finalize the analysis for the best migration path.

The ecological barriers which has the largest influence for connectivity are those patches who have the largest resistance value in the resistance surface (which is developed by least cost corridor model), normally are roads, constructions, etc. If we can remove these barriers, the connectivity will increase, so local stakeholders have to consider these factors when they want to apply effective protection measures to improve the connectivity.

(2) Determination of best route and least-cost distance

To determine the best route and least-cost distance, we have to calculate the cost-weighted distance (CBD) from every grid to core area and generate the grid map, and then add the cost to form the least-cost distance (LCD). In a core area, the least resistance surface data will be calculated towards each pixel, then the cumulative resistance will be calculated and the least-cost distance of the best route will be generated accordingly.

$$
L C D^{\prime}=C W D 1_{M I N}+C W D 2_{M I N}+\left(L * R^{\prime}\right)
$$

$L C D^{\prime}$ is the least-cost distance of the best route, $C W D X_{\mathrm{MIN}}$ is the minimum CWD value in the patch $\mathrm{X}, \mathrm{L}$ is the longest axis length in the searching area and $R^{\prime}$ is the resistance value in passing the barrier.

(3) Selection of best corridor based on connecting effectiveness

$\triangle L C D$ is used to evaluate the effectiveness in every repair point. Domain analysis (by standard GIS) is applied to every pixel in the surface landscape of the grid map, and a score will be given. The barrier point which has the highest score will be repaired and removed, so the repair cost will be the lowest when the eco-corridor go through this point.

$$
\triangle L C D=L C D-L C D^{\prime}
$$

$\triangle L C D$ is the connecting effectiveness for repairing unit distance in the study area, $\triangle L C D$ has positive relationship with the improvement of LCD and has relationship with unrepaired effective distance. If $L C D^{\prime}$ is lower than $L C D$, then it is considered that the ecological renovation in the selected route will reduce the effective distance and increase the connectivity between two patches.

\section{Construction of index system for resistance surface factors.}

A three-level index system which had 11 indices was constructed in terms of land utilization, disturbance intensity and linear surface feature's resistance to reflect the resistance surface of 
human disturbance. The values of the indices were standardized to make them between 1 and 100, then the resistance surface of land in China was generated by coupling with GIS spatial analysis. Expert scoring method was adopted to assign the weight of the indices, which was shown below in Tab.1.

The data used in the calculation came from population statistics and grid data, topographic data (1:250000), human residence distribution, river network, road network, GDP data, DEM data, vegetation coverage data (2000-2010), NOAA DMSP-OLS data (1992-2012).

Tab 1. Index system for resistance surface factors

\begin{tabular}{llllll}
\hline Level 1 & $\mathrm{w}_{1}$ & Level 2 & $\mathrm{w}_{2}$ & Level 3 & $\mathrm{w}_{3}$ \\
\hline Land utilization & 0.4 & Construction & 0.6 & Urban construction & 0.4 \\
& & & & Rural construction & 0.3 \\
& & & & Others & 0.3 \\
& & Agriculture & 0.4 & Dry farmland & 0.4 \\
& & & Irritated farmland & 0.3 \\
& & & Others & 0.3 \\
\hline Disturbance intensity & 0.3 & GDP & 0.3 & & \\
& & Population density & 0.3 & & \\
\hline linear surface feature & 0.3 & Road network density & 0.5 & & \\
& & River density & 0.5 & & \\
\hline
\end{tabular}

\section{Results and Discussion}

Till the end of 2013, 2640 nature reserves had been established by relevant ministries in China, and the total area added up to 14,970,000 hm2, in which there were 335 national reserves with an area of $9,310,000 \mathrm{hm} 2$, covering $62 \%$ of the total area; province or city/county level reserves had $9,310,000 \mathrm{hm} 2$ and covered $38 \%$ of the total area.

Our research focused on the land nature reserves which areas were larger than $50 \mathrm{Km} 2$. There were 205 nature reserves were included in the research, in which 65 were national level, and covered $19.4 \%$ of the total national reserves.

The 205 nature reserves were considered as the core of protection and based on the resistance surface as well as the database of the nature reserves, the eco-corridors between adjacent conservation areas were extracted by applying the minimum cost-distance method, the spatial pattern of eco-corridor in Northeast China was shown in Fig.1. 


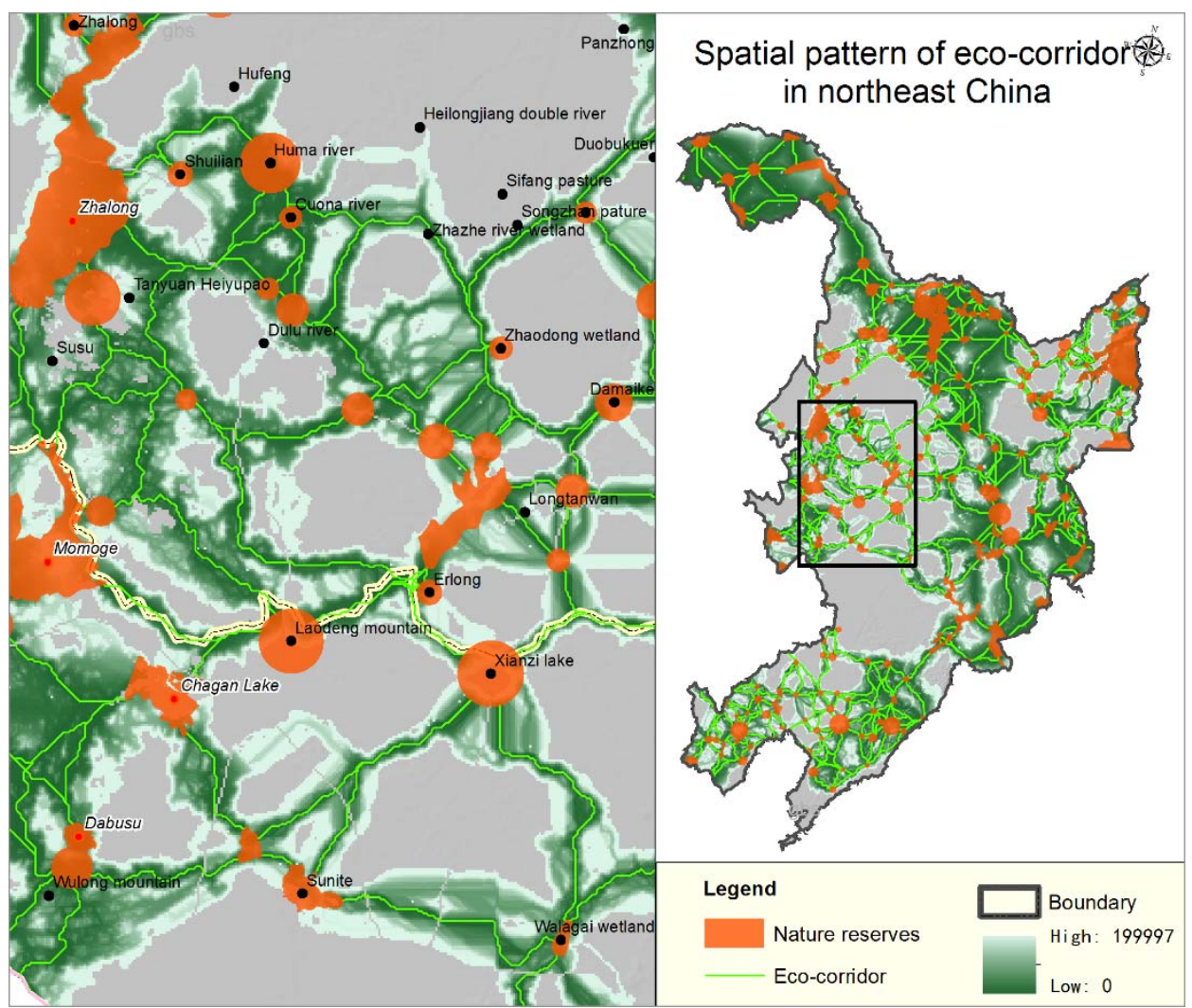

Fig.1.Spatial pattern of eco-corridor in Northeast China

Our study focus on the construction of eco-corridor on large scale. As for the practical construction of corridors on small scale, we should also consider the life habits of the animals, the characteristics of different habitats, etc; long term follow-up studies are needed, and the influence of climate change should be considered too.

(1) The construction of eco-corridors should be considered in enacting national ecological red line policy

The construction of eco-corridors should be closely connected with relevant policies. Nature reserves will be classified as red line area, however, the nature reserves in the red line area are separated from each other because of the absence of interconnection which will lead to negative effect to bio-diversity protection, so we suggest add relevant contents of eco-corridor in enacting national ecological red line.

(2) Eco-corridor should be considered in the studies of global climate change

Climate change is recognized as an important reason for bio-diversity loss besides habitat damage. To adapt to the global warming caused by climate change, land animals have to migrated to high altitudes and latitudes; meanwhile, suitable planting area will move to high latitudes, which will lead to damage to original eco-corridors and interrupt the migration of animals. So, we suggest to consider the influence on eco-corridors in the studies of global climate change.

(3) The construction of ecological corridors should become the starting point of ecological recover

China are carrying out many ecological recover projects, and the government has invested large fund on ecological construction. We suggest local government consider the construction of eco-corridors in planning detailed ecological recover projects; some key projects which will benefit for the national corridor and red line system should be identified and constructed as priority.

\section{Acknowledgment}

Our research was sponsored by the Study on the Constructing Techniques of Eco-corridors Based on Ecological Protection Red Lines, which is one of the Fundamental Scientific Research Projects of State Level Research Institutes. 


\section{References}

[1] Shuangcheng Li, Yueqing Xu, Qiaofu Zhou, Lei Wang. Statistical Analysis on the Relationship between Road Network and Ecosystem Fragmentation in China. Progress in Geography [J], 2004, 23(5): 78-85.

[2] Shufeng Ye, Dewen Ding, Wenhua Wang. Large-scale Estuarine Engineering and Estuarine Habitat Fragmentation of Water Body in the Yangtze River Estuary. Acta Ecologica Sinica [J], 2005, 25(02):268-272.

[3] Beier P, Majka DR, Spencer WD. Forks in the Road: Choices in Procedures for Designing Wild land Linkages. Conservation Biology [J], 2008, 22, 836-851.

[4] Bowers K, McKnight M. Reestablishing a Healthy and Resilient North America-Linking Ecological Restoration with Continental Habitat Connectivity. Ecological Restoration [J], 2012, 30, 267-270.

[5] Chettri N, Sharma E., Shakya B, Bajracharya B. Developing Forested Conservation Corridors in the Kangchenjunga Landscape, Eastern Himalaya. Mountain Research and Development [J], 2007, 27, 211-214.

[6] Driezen K, Adriaensen F, Rondinini C, Doncaster CP, Matthysen E. Evaluating Least-cost Model Predictions with Empirical Dispersal Data: A Case-study Using Radio Tracking Data of Hedgehogs (Erinaceus europaeus). Ecological Modelling [J], 2007, 209, 314-322.

[7] Kongjian Yu, Dihua Li, Tiewu Duan. Landscape Approaches in Biodiversity Conservation. Biodiversity Science [J], 1998, 6, 205-212.

[8] Zhengjie Zhao. Zoography of Valuable and Rare Animals in Northeast China. Beijing, China Forestry Press [M], 1999. 